\title{
Drug Use and Sources of Drug Information Among Secondary School Students in Imo State, Nigeria
}

\author{
Cajetan I. Ilo, PhD \\ Ignatius O. Nwimo PhD \\ Department of Human Kinetics and Health Education, \\ Ebonyi State University, Ebonyi State, Nigeria
}

doi: 10.19044/ejes.v4no1a76 URL:http://dx.doi.org/10.19044/ejes.v4no1a76

\begin{abstract}
This study was an investigation into drug use and sources of drug information among secondary school students in Imo State, Nigeria. A sample of 1400 students, aged 16-17 years was studied. Percentages were used to describe the students' drug use and sources of drug information. Chisquare was used to verify the four hypotheses postulated for the study. Results showed that the main drugs the students who took part in the study used included analgesics, stimulants, anti-malaria, alcohol, worm expellants, nasal decongestants, sleeping pills, laxatives, and anti-biotics and their main sources of drug information included print media, television, radio, and friends and peers. Chi-square tests indicated that the differences in the use of drugs between boys and girls were significant in most cases. It is recommended that drug education be made an integral part of secondary school curriculum.
\end{abstract}

Keywords: Drug use, Sources of information, Secondary school students, Imo State.

\section{Introduction}

Although the history of drug use is centuries old, during mid 1960's a widespread introduction of marijuana, and subsequently other illicit drugs, occurred among the young. Since the first experience with drugs occurs most frequently at the age of mid adolescence, that is, between 15 and 19 years (Hotujac, Sagud, Hotujac, 2002; Warner, Kessler, Huges, Anthony, \& Nelson, 1995), the highest prevalence of drug use is between the age of 18 and 25 years, and later tends to decrease, being rare after age of 35 years (Russel, Newman, \& Bland, 1996). Therefore, adolescents, being in intensive physiological and psychological growth transformation, seem to be the most vulnerable population regarding drug use (Parrish, 1994). Drug use 
is a consequence of interaction between complex circumstances as individual predisposition, personality traits, family and peer influence and the role of an individual in a society (Davies, 1994). Surveys (Wright, 1995; Ogel, Tamar, Evren, \& Cakmak, 2000; Ogel, Tamar, Evren, Cakmak, 2001; Read, Wood, Davidoff, McLacken, \& Campbell, 2002; Igwe \& Ojnnaka, 2010) suggest that in both in-and out-of-school adolescents, the socially acceptable drugs like alcohol and cigarettes are commonly used. The patients interviewed in a study (Johnston, O’Malley, Bachman, \& Schulenberg, 2008) illustrate the important 'gateway' theory of drug progression. Psychological dynamics influencing drug use identified included peer pressure, lack of selfconfidence, reduction of stress and frustration, curiosity and search for excitement, experimentation and conduct problems while social factors include poverty, family problems, and social acceptability of local alcoholic drinks like palm-wine (Freud, 1953; Johnston, O’Malley, Bachman, \& Schulenberg, 2008, Ndu, Ndu, Olarewaju \& Somoye, 2009).

Secondary school students are an at-risk population for substancerelated problems (Simons, Gaher, Correia, Hansen, \& Christopher, 2005). The consumption of alcohol, legal and illegal drugs in the secondary school population tends to be growing (Simons, Gaher, Correia, Hansen, \& Christopher, 2005; Read, Wood, Davidoff, McLacken, \& Campbell, 2002) and has become a source of worry in many countries. The passage from junior secondary school to senior secondary school is usually marked by an increment in frequency of opportunities for peer interaction and in importance of the role of peer norms (Read, Wood, Davidoff, McLacken, \& Campbell, 2002). Direct (or active) peer influences explicitly focus on getting a person to drink. Also, peers, through their own actions, may provide information about which behaviours are accepted and admired, which is considered appropriate in a given social context, and therefore what behaviours are likely to lead to social acceptance and reinforcement. Each of these indirect influences set the stage for anticipated social reinforcement (Borsari \& Carey, 2001). Lewis and Neighbors (2004) demonstrated that men and women overestimated the drinking pattern of their male and female peers.

An estimation tracking the prevalence of drug use among adolescents seems to be very important. While some data indicate decrease in alcohol abuse among adolescents in recent years, it is not the case with other drugs, especially with cannabis and over-the-counter drugs, including those labeled prescription drugs (National Institutes of Health, 2005; Wright, 1995). However, it could be basically difficult to estimate the number of secondary school students using drugs and perhaps a survey like the present one might be a better way of establishing the proportion of secondary school students in Imo State who use drugs. According to Katalini, Kuzman, and Raja (1998), 
data estimating illicit substance use are derived from hospital records of medically treated drug users and from police records. The real number of drug users in Imo state, Nigeria is unknown. Other systems currently available to gauge drug use levels and trends, such as national household survey of drug use estimating the drug use in the total population (Warner, Kessler, Huges, Anthony, \& Nelson, 1995) have not been performed in Imo State till date. The only tracing study of prevalence and perceived health effects of alcohol is that Ebrim and Morankinyo (2011) conducted in Owerri, the capital city of Imo State used male undergraduate students. Since this study was delimited to alcohol among male undergraduates, it may not have been comprehensive enough to make a valid judgment on drug use among adolescents in Imo State.

Previous studies conducted in different regions of the globe reported that the prevalence of drug use was significantly reducing (Martinez, del Rio, Lopez, \& Alvarez, 1999; Gfroerer, Greenblatt, Wright, 1997; Webb, Ashton, Kelly \& Kamali, 1996; Thomas, Goddard, Hickman, \& Hunter, 1993; Macfadden \& Woody, 2000). Views about alcohol and other drugs and rates of use may vary among gender and age groups (Ogel, Tamar, Evren, \& Cakmak, 2001). Lifetime prevalence of illicit drug use was found 3.3\% among high school students (15-17 year age group) in a study done in 15 different cities of Europe in 1998 (Ogel, Tamar, Evren, \& Cakmak, 2000). The above scenario is observed in Europe and other developed countries and documents of drug use and sources of drug information among secondary school students in Imo state are rarely available. It is because of this scenario that this study was conducted to; at least, provide baseline information on the drug use and sources of drug information among secondary school students in Imo State.

The purpose of this study, therefore, was to investigate drug use and sources of drug information among secondary school students in Imo State. Two hypotheses were postulated for verification at $\mathrm{p}<.05$, thus:

1. There is no significant difference between secondary school boys and girls in Imo State in their use of individual drugs of the study, and

2. There is no significant difference between secondary school boys and girls in Imo State in their sources of individual drug information of the study.

The study might form a baseline data on drug use and sources of drug information among secondary school students in Imo state. However, the findings of the study might be of immense benefit to health education curriculum planners so as to drive drug education into any future health education curriculum for secondary schools. 


\section{Methodology}

Between September and December 2008, a cross sectional survey was carried out among 1400 (boys 700, girls 700) students randomly drawn from 20 (10 rural, 10 urban) co-educational secondary schools in Imo state. The secondary schools were selected from two (Owerri and Okigwe) out of three education zones in Imo state. In each school 70 boys (SS2 35, SS3 35) and 70 girls (SS2 35, SS3 35) were randomly selected using systematic random sampling technique. Compiling two lists one for boys and the other for girls, with respect to grade, facilitated this.

The researchers used a self-developed questionnaire entitled: students' drug use and sources of drug information questionnaire (SDUSDIQ), which consisted of 25 items arranged in two sections; A and B. Section A, contained three questions about the gender, age and class of the students. Section B, consisted of 22 items on students' drug use and sources of drug information of which 14 items were meant to elicit information of the drugs the students use and 8 items enquired about the students' sources of drug information.

Five experts in health education from two institutions of higher learning in Enugu State were used for validating the SDUSDIQ. Thirty secondary school students (15 each from a rural and an urban school) of both genders (graders 11 and 12) in Ebonyi state were used for test of reliability. The data yielded a reliability coefficient of 0.83 . This was considered adequate for the study.

Permission was granted from the principal of each secondary school included in the study prior to data collection. A consent note with the explanation for the research purpose, method of response and assurance of anonymity was attached to each copy of the SDUSDIQ. The teachers in charge of the classes used in the study assisted the researchers in administering the SDUSDIQ on the students. The students were allowed 30 minutes during break period in a school day to complete the SDUSDIQ.

In analyzing the data collected, the completed copies of the SDUSDIQ were examined for completeness of responses and copies that had incomplete responses were discarded. Out of 1400 copies of the SDUSDIQ administered; 1151 (boys 495, girls 656) representing about 82.2\% return rate, were used for analysis. Percentages were used to describe the students' drug use and sources of drug information. Statistical differences between variables were tested using measures of association, including the $\chi^{2}$ chisquare statistic. An alpha level of 0.05 was set for the chi-square $\left(\chi^{2}\right)$ tests. All data analyses were done with Statistical Package for Social Sciences (SPSS) Version 20.0 for Windows. 


\section{Results}

Table 1: Drugs used by students

\begin{tabular}{|c|c|c|c|c|}
\hline \multirow{3}{*}{ Drugs } & \multicolumn{3}{|c|}{ Responses } & \multirow[b]{3}{*}{$\chi^{2}$ Value } \\
\hline & Overall & Boys $(n=495)$ & Girls $(n=656)$ & \\
\hline & $\%$ & $\%$ & $\%$ & \\
\hline Analgesics & 92.4 & 87.1 & 96.3 & $33.17^{*}$ \\
\hline Anti-malaria & 87.3 & 78.4 & 94.1 & $61.11^{*}$ \\
\hline Worm expellants & 56.6 & 51.5 & 60.4 & $8.66^{*}$ \\
\hline Inhalants (e.g., nasal decongestants) & 55.9 & 63.2 & 50.3 & $18.64 *$ \\
\hline Cough mixtures & 45.4 & 45.7 & 45.1 & 0.01 \\
\hline Thalazole & 48.5 & 42.6 & 52.9 & $11.52 *$ \\
\hline Purgatives and laxatives & 53.3 & 60.4 & 48.0 & $16.85^{*}$ \\
\hline Sleeping pills (e.g., valium) & 55.1 & 46.1 & 61.9 & $27.99 *$ \\
\hline Narcotic (e.g., pain relievers) & 26.3 & 21.8 & 29.7 & $8.68 *$ \\
\hline Anti-biotics (e.g., ampiclox) & 52.3 & 27.7 & 70.9 & $209.41 *$ \\
\hline Stimulants (e.g., kola nuts) & 87.9 & 96.8 & 81.3 & $62.58 *$ \\
\hline Alcohol (e.g., beer, palm wine) & 76.0 & 90.3 & 65.2 & $95.83 *$ \\
\hline Tobacco (cigarette) & 22.1 & 32.5 & 14.2 & $54.24 *$ \\
\hline Marijuana (we-we) & 5.2 & 9.7 & 1.8 & $109.02 *$ \\
\hline
\end{tabular}

* Significant at $p<.05$

Percentages of use of drugs and results of $\chi^{2}$-tests are listed in Table 1. It could be observed that more than three quarters of the students used analgesics, stimulants, anti-malaria, and alcohol. However, more than half the proportion of students used worm expellants, nasal decongestants, sleeping pills, laxatives, and anti-biotics. When boys were compared with girls, girls used analgesics, anti-malaria, worm expellants, sleeping pills, and anti-biotics more than boys; but boys used nasal decongestants, laxatives, stimulants and alcohol more than girls. Chi-square tests indicated all differences in the use of drugs between boys and girls were significant except in the use of cough mixtures.

Table 2: Sources of drug information

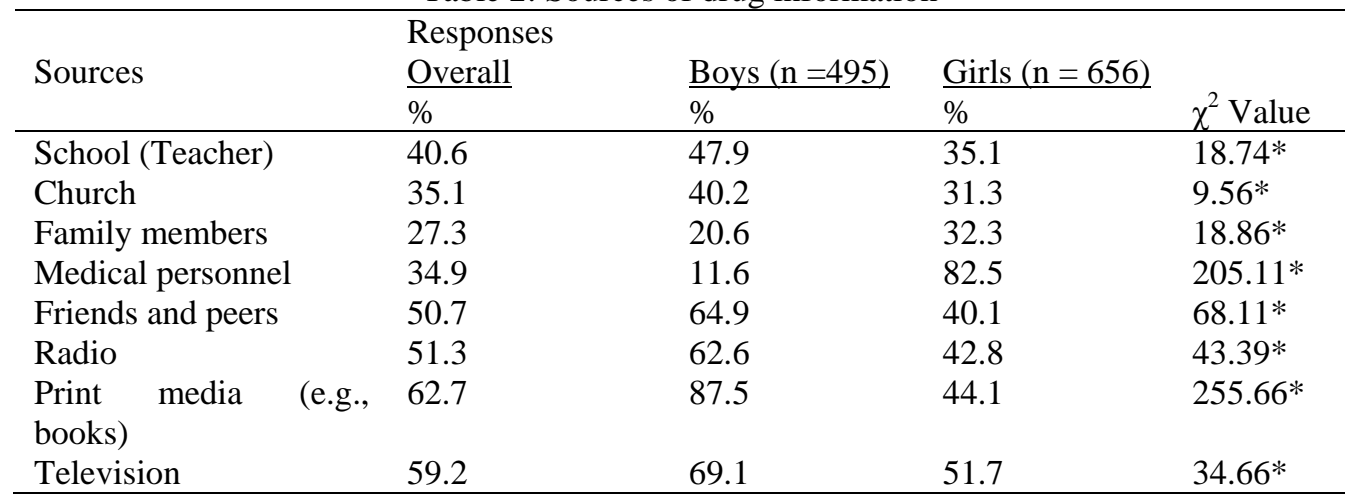


Percentages of sources of drug information and results of $\chi^{2}$-tests are listed in Table 2. The students' main sources of drug information included print media (e.g., books), television, radio, and friends and peers. When boys were statistically compared to girls; the boys were superior to girls in most sources of drug information especially print media, television, radio, and friends and peers; but girls were superior in one important source of drug information namely; the medical personnel. Chi-square tests indicated differences in all sources of drug information between boys and girls were significant.

\section{Discussion}

The present study determined drug use and sources of drug information among secondary school students in Imo state. It was observed that more than $75 \%$ of the students used analgesics, stimulants, anti-malaria, and alcohol. However, more than $50 \%$ the proportion of students used worm expellants, inhalants, sleeping pills, laxatives, and anti-biotics. When boys and girls were compared statistically it was observed that all differences were significant $(\mathrm{p}<.05)$ except in the use of cough mixtures (Table 1$)$. It is a common experience that analgesics and the other drugs used by the students could be obtained in the open market provided the user has the need for such drugs. Therefore, it was not surprising that the students commonly used the drugs since most of these drugs are always available for any person who desires to grab them. It was not also misleading to observe that girls were significantly more than boys to have used these drugs, except alcohol and stimulants where boys outwitted girls. The most astonishing finding among the students was the use of inhalants, the proportion of students who used the drug notwithstanding. The use of inhalants at the secondary school level of education could suggest that the students might in the future "graduate" to using potentially more dangerous substances as they age.

Findings from previous studies (Boyd, Esteban, \& Teter, 2006; Crouch, Caravati, \& Booth 2004; Gilchrist, Schinke, Trimble, \& Cvetkovich, 1987; Wu, Schlenger, Ringwalt, 2005) did not lend credence to the findings of the present study where they found in their individual studies that there were no significant gender differences in the use of drugs. However, one possible explanation that could be made regarding this variation in the findings of the present study with those of the previous studies is the difference in the settings where the studies were conducted. The previous studies were conducted in developed countries, where perhaps, drug education may have been an integral part of the school curriculum unlike the setting of the present study where drug education is still a mirage. Therefore, the variation in the findings of the previous studies with those of the present study is plausibly acknowledged. 
From the results, it is evident that the vast majority of the students received their information on drugs from the mass media and friends and peers (Table 2). Very little communication regarding drugs occurred between the students and their parents, teachers or health workers (e.g., doctors and nurses). This scenario, most often, is as a result of lack of interest on the part of teachers, culture on the part of parents and non-involvement in the organization of school health services on the part health workers. This suggests the importance of involving parents, teachers, health workers and even students in drug education programmes. The stimulation of interest in parents, teachers and health workers concerning drugs may help them educate themselves and their children/or students regarding the subject matter. This suggestion has worked in other health-related matters (Maswanya, Moji, Aoyagi, Yahata, Kusano, Nagata, Izumi, \& Takemoto, 2000). The findings were consistent with previous findings that most people learned about drug from mass media and friends and not from official agencies so that is where one should start if one wants to change a drug culture (National Institutes of Health, 2005, Weiss \& More, 1995). However, the implication of the findings of the present study underscores the need for a formal drug education in the secondary school health education or health science curriculum where teachers might have the opportunity of providing scientific information on drug and drug-related matters to the students.

\section{Conclusion and Recommendation}

One important way of reducing the use of drugs among both in-and out-of-school adolescents is through provision of worthwhile information on the subject matter. When people are provided with accurate information on any health-related matter, they become well able to make informed decisions about a given health matter (Action Health Incorporated, 2003). The findings of this study demonstrated that students in secondary schools in Imo State used a wide range of drugs and received their drug information mainly from print media (e.g., books), television, radio, and friends and peers and rarely did they receive drug information from teachers and medical personnel. There were statistical significant differences in the use of drugs between boys and girls with the exception of cough mixtures. Girls were more likely than boys to receive drug information from medical personnel. The results of the study suggest there may be need for monitoring of and prevention efforts aimed at reducing drug use among students.

There is considerable rationale to include drug education as an integral part of secondary school curriculum in order to get every teacher compulsorily involved in the provision of drug information. The results of the study may not be extrapolated to other population groups in Nigeria who may differ substantially in age, sex distribution and economic status. The 
students surveyed represent an important group of the Nigerian population and information generated will be useful in the planning of future drug programmes in secondary schools in Imo State and other states in Nigeria.

\section{References:}

Action Health Incorporated. (2003). Comprehensive sexuality education. Lagos: Action Health Incorporation.

Borsari, B., \& Carey, K.B. (2001). Peer influences on college drinking: A review of the research. Journal of Substance Abuse, 13(4), 391-424.

Boyd, C.J., Esteban, M.S., \& Teter, C.J. (2006). Medical and non medical use of prescription pain medication by youth in a Detroit-Area public school district. Drug and Alcohol Dependence, 81(1), 37-45.

Crouch, B.I., Caravati, E.M., \& Booth, J. (2004). Trends in child and teen non-prescriptive drug use reported to a regional poison. American Journal of Health Systems Pharmacology, 61(12), 1252-1257.

Davies, R. B. (1994). Personality, lifestyles, alcohol and drug consumption in a sample of British medical students. International Journal of Addiction, 29(3), 303-308.

Ebrim, I.C.C., Morankinyo, M. (2011). Prevalence and perceived health effect of alcohol use among male undergraduate students in Owerri, SouthEast Nigeria: A descriptive cross-sectional study. BMC Public Health, 11, 118. doi:10.1186/1471-2458-11-118

Freud, S. (1953). The transmission of puberty. In J. Strachey (Ed.). The standard edition of the concrete psychological works of Sigmund Freud (p. 7). London. Hogarth Press.

Gfroerer, J.C., Greenblatt, J.C., \& Wright, D.A. (1997). Substance use in the US college-age population: Differences according to educational status and living arrangement. American Journal of Public Health, 87(2), 62-65.

Gilchrist, L.D., Schinke, S.P., Trimble, J.E., \& Cvetkovich, G.T. (1987). Skills enhancement to prevent substance abuse among American Indian adolescents. International Journal of Addiction, 87(22), 869-879.

Hotujac, A., Sagud, M., \& Hotujac, L.J. (2002). Drug use among Croatian students. College Anthropology, 24(1), 61-68.

Igwe, W.C., \& Ojnnaka, N.C. (2010). Mental health of adolescents who abuse psychoactive substances in Enugu, Nigeria: A cross-sectional study. Italian Journal of Pediatrics, 36, 53. Retrieved June 2, 2015, from http://www.ncbi.nlm.nih.gov/pmc/articles/PMC2928240/

Johnston, L. D., O’Malley, P. M., Bachman, J. G., \& Schulenberg, J. E. (2008). Monitoring the Future national survey results on drug use, 19752007: Volume I, Secondary school students (NIH Publication No. 086418A). Bethesda, MD: National Institute on Drug Abuse. 
Katalini, D., Kuzman, M., \& Raja, D. (1998). Report on the in-and outpatients diagnosed as addicted to drugs in Croatia in 1988. Zagreb: National Institute on Substance Abuse.

Lewis, M.A., Neighbors, C. (2004). Gender-specific misperceptions of college student drinking norms. Psychology of Addictive Behaviour, 18(4), 334-339.

Macfadden, W., \& Woody, G.E. (2000). Cannabis-related disorders. Philadelphia: Lippincott Williams \& Wilkins.

Martinez, J.M., del Rio, M.D.R., Lopez, N., \& Alvarez, F.J. (1999). Illegal drug-using trends among students in a Spanish University in the last decade (1984-1994). Substance Use and Misuse, 34(4), 1281-1297.

Maswanya, E.S., Moji, K., Aoyagi, K., Yahata, Y., Kusano, Y., Nagata, K., Izumi, T., \& Takemoto, T. (2000). Knowledge and attitudes toward AIDS among female college students in Nagasaki, Japan. Health Education Research, 15(1) 5-11.

National Institutes of Health. (2005). Prescription drugs: Abuse and addiction. Washington, D.C.: U.S. Department of Health and Human Services.

Ndu, F.O., Ndu, L.O., Olarewaju, A.O., \& Somoye, F. (2009). Basic science: integrated science course for junior secondary schools. Ikeja: Longman Nigeria Plc.

Ogel, K., Tamar, D., Evren, C., \& Cakmak, D. (2000.) Prevalence of cigarette, alcohol and substance use among high school youth in Istanbul. Clinic Psychiatry, 3(5), 242-245.

Ogel, K., Tamar, D., Evren, C., \& Cakmak, D. (2001). Prevalence of cigarette, alcohol and substance use among high school youth. Turkish Psychiatry, 12(2), 47-52.

Parrish, S. K. (1994). Drug misuse among college students. Alcohol, 11(6), 453-459.

Read, J.P., Wood, M.D., Davidoff, O.J., McLacken, J., \& Campbell, J.F. (2002). Making the transition from high school to college: The role of alcohol related a social influence factor in student's drinking. Substance Abuse, 23(1), 53-65.

Russel, J. M., Newman, S.C., \& Bland, R.C. (1996). Prevalence of cigarette, alcohol and substance use among medical students in University of Dokuz Eylul. Acta Psychiatry of Scandinavia, 76(1), 54-59.

Simons, J.S., Gaher, R.M., Correia, C.J., Hansen, C.L., \& Christopher, M.S. (2005). An affective-motivational model of marijuana and alcohol problems among college students. Psychology and Addictive Behaviour, 19(3), 326334. 
Thomas, M., Goddard, E., Hickman, M., \& Hunter, P. (1993). General household survey: 1992. London: Office of Population Censuses and Surveys.

Warner, L. A., Kessler, R. E., Huges, M., Anthony, J. C., \& Nelson, E. B. (1995). Correlates of alcohol, tobacco and marijuana use among Scottish postsecondary helping-profession students. Archive of General Psychiatry, 52(3), 219-222.

Webb, E., Ashton, C.H., Kelly, P., \& Kamali, F. (1996). Alcohol and drug use in UK university students. The Lancet, 348, 922-925.

Weiss, S., \& Moore, M. (1995). Sources of alcohol and drug information among Israeli urban adolescents. Journal of Drug Education, 25(3), 211-222. Wright, J. D. (1995). Prevalence of substance use among high school students in Sivas city. British Medical Journal, 7(5), 20-27.

Wu, L.T., Schlenger, W.E., \& Ringwalt, C.L. (2005). Use of nitrite inhalants ("poppers") among American youth. Journal of Adolescent Health, 37(1), 52-60. 